\section{Respiratory insufficiency and limb muscle weakness in adults with Pompe's disease}

\author{
N. Pellegrini*, P. Laforet ${ }^{\#}$, D. Orlikowski*, M. Pellegrini*, C. Caillaud ${ }^{\top}$, B. Eymard\#, \\ J-C. Raphael* and F. Lofaso ${ }^{\star,+}$
}

ABSTRACT: The objective of the present study was to prospectively evaluate relationships linking age, respiratory function and locomotor function in 29 outpatients with late-onset Pompe's disease and to retrospectively determine clinical outcomes.

Using univariate regression analysis, vital capacity (VC) was weakly, but significantly, correlated to shoulder motility, Walton score and lower-limb Modified Medical Research Council score. Six patients were able to walk without a walking aid and with only the help of a handrail on the stairs (Walton score $=\mathbf{3}$ ), although VC was $<\mathbf{5 0} \%$. No parameters were significantly correlated with age.

As assessed retrospectively, VC and locomotion deteriorated over time in most patients. In contrast, among the 16 patients started on invasive or noninvasive ventilation with VC monitoring, eight had a VC increase at the first measurement time-point.

The absence of correlation with age and the presence, in some patients, of severe respiratory insufficiency without severe limb girdle muscle weakness indicate that respiratory function should be monitored independently from the degree of peripheral muscle weakness. Mechanical ventilation and tracheostomy may improve vital capacity and should, therefore, be taken into account when evaluating treatments for the adult form of Pompe's disease.

KEYWORDS: Acid maltase deficiency, a-glucosidase, glycogen storage disease type II, neuromuscular disease, Pompe's disease, pulmonary function

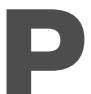

ompe's disease, also named acid maltase deficiency or glycogen storage disease type II, is an autosomal recessive disorder characterised by a deficiency in the lysosomal enzyme acid $\alpha$-glucosidase (GAA). The spectrum of this disease is wide and varies from a rapidly progressive infantile disease with cardiorespiratory insufficiency, which is usually fatal before $1 \mathrm{yr}$ of age [1], to a slowly progressive adultonset disease with muscle weakness, respiratory insufficiency $[1,2]$ and sleep-disordered breathing [3]. Adults typically present with progressive myopathy that may resemble limb-girdle muscular dystrophy [4]. However, both the presenting symptoms and the clinical outcomes in adults seem to vary widely. Although respiratory muscle involvement is rarely inaugural $[5,6]$, it may occur early in the course of the disease and may cause death. These characteristics, and the likelihood that new treatments recently tested in infantile and juvenile Pompe's disease [7-10] will require evaluation in adult-onset disease, indicate a need for investigations into the relationships

For editorial comments see page 984 . between respiratory muscle weakness and weakness in other muscles. This will clarify outcomes in adults and assess the effects of both noninvasive mechanical ventilation (MV) and tracheostomy.

The objectives of the present study were to evaluate relationships linking age, respiratory function and locomotor function, and to assess clinical outcomes in the adult form of Pompe's disease.

\section{METHODS}

In total, 29 patients with late-onset Pompe's disease were investigated prospectively as part of routine follow-up. Patients who required MV or respiratory function evaluation were studied at the Raymond Poincaré Teaching Hospital (Garches, France) and the other patients at the Myology Institute, Pitié-Salpêtrière Teaching Hospital (Paris, France). The diagnosis was confirmed by assessment of low GAA activity in leukocytes in all patients [11] and by identification of the gene mutations in 11 patients [12]. Physical examinations were carried out by a neurologist (B. Eymard or P. Laforet) or physical therapist (N. Pellegrini).

\section{AFFILIATIONS}

*Intensive Care Unit and Dept of Physiology-Functional Testing, Garches Institute and Centre for Technological Innovation, Garches, \# Institut de Myologie, Hôpital PitiéSalpêtrière, and

- Laboratoire de Génétique, Institut Cochin de Génétique Moléculaire, Paris, and

+'Inserm UMR 651, Créteil, France.

CORRESPONDENCE

F. Lofaso

Service de Physiologie-Explorations Fonctionnelles,

Hôpital Raymond Poincaré

92380 Garches

France

Fax: 33147107943

E-mail: f.lofaso@rpc.ap-hop-paris.fr

Received:

February 212005

Accepted after revision:

September 132005

European Respiratory Journal

Print ISSN 0903-1936

Online ISSN 1399-3003 


\section{Locomotor function}

The evaluation consisted of an interview regarding occupational activities, ability to swallow without difficulty, ability to control urination and presence of chronic pain (e.g. in the back, neck or muscles). Functional activity was assessed using the Gardner, Medwin and Walton score (where $0=$ normal and $10=$ bed bound) [13]. Muscle power of the quadriceps femoris, hip flexors and gluteus medius on both sides of the body was graded using the Modified Medical Research Council (MMRC) scale, which has been used in muscle diseases, such as Duchenne muscular dystrophy [14]. The MMRC scale has six grades (0 to 5) followed by + or - for some values (e.g. 1+, 2-, $2+, 3-, 3+)$. The current authors transformed + and - to +0.33 and -0.33 , respectively. For each muscle, the mean value for the right and left limbs was used. Therefore, the total MMRC score could range from 0 to 15 . The range of active shoulder abduction with the elbow extended was measured in degrees $\left(0-180^{\circ}\right)$, and the mean of the right and left side was used. Care was taken to check that limitation was not due to pain or to skeletal conditions such as frozen shoulder. Therefore, shoulder abduction evaluated the synergic contraction of the deltoid, supraspinatus, serratus anterior and trapezius.

\section{Lung and respiratory muscle function}

Sniff nasal pressure $\left(P_{\mathrm{sn}}\right)$ and maximal inspiratory pressure (PImax) were both measured from the functional residual capacity (FRC) in a standard manner. As previously described, PImax is an isometric manoeuvre and $P_{\text {sn }}$ a quasi-isometric manoeuvre $[15,16]$. These variables were obtained for the patients evaluated at the Raymond Poincaré Teaching Hospital. Psn was measured during 10 maximal sniffs [17] PImax was measured using a flanged mouthpiece with the manoeuvres repeated at least three times, or until two identical readings were obtained [18]. All signals were measured using a differential pressure transducer (Validyne, Northridge, CA, USA), amplified by a carrier amplifier (Validyne) and passed via an analogue-digital board to a computer running Acqknowledge software (Biopac System, Santa Barbara, CA, USA). Patients received strong verbal encouragement with visual feedback, as in previous studies [19]. The best value of the two measurement methods was taken as the PImax.

For the patients who accepted, transdiaphragmatic pressure $(P$ di) was obtained by measuring the differential between gastric pressure and oesophageal pressure using a cathetermounted pressure transducer system (Gaeltec, Isle of Skye, UK). The catheter was inserted through the nose, following administration of local anaesthesia, to the nasal mucosa. The position of the catheter was assessed by asking the subject to perform sharp sniff manoeuvres, whilst observing signal deflection. The oesophageal and gastric transducers were advanced into the stomach, i.e. until a positive deflection occurred while one of the operators applied gentle pressure to the patient's stomach, and the catheter was then withdrawn until a drink of water induced a sharp rise in the proximal transducer pressure (resulting from muscular contraction of the oesophagus) without any concomitant modification of the distal transducer pressure. This indicated that the proximal transducer was in the oesophagus and the distal transducer in the stomach. An occlusion test was carried out to assess the validity of the oesophageal pressure measurement [20].
Following this, cervical magnetic phrenic nerve stimulation, via a $90 \mathrm{~mm}$ circular coil powered by a Magstim stimulator (Magstim Company, Whitland, UK), was used to determine the twitch transdiaphragmatic pressure (TwPdi) [21]. This is a sensitive and reliable nonvolitional technique for assessing diaphragm function [21]. All the magnetic stimulations were applied at FRC, determined by the end-expiratory oesophageal pressure level $[19,22]$. Mean TwPdi was calculated from at least five phrenic nerve stimulations at maximal power output. $P$ di pressure change was also measured during sniff manoeuvres and maximal inspiratory manoeuvres were performed as described above to obtain maximal transdiaphragmatic pressure (Pdimax). Spirometry and lung volume measurements were performed according to standard guidelines at both hospitals and reported as per cent predicted [23].

\section{Retrospective assessment of muscle weakness progression}

The medical records of the study patients were reviewed in detail to obtain information on outcomes reflecting the progression of muscle weakness.

\section{Statistical analysis}

Data were expressed as mean \pm SD. The differences between patients who did and did not use MV were compared using an unpaired t-test. Fisher's exact test was used to compare prevalence rates in the two groups. In addition, using the values at the time of the study for least-square simple linear regression analysis, the present authors looked for correlations between age and other data, as well as between vital capacity (VC) and inspiratory muscle and locomotor data. A full-model, stepwise, multiple linear regression analysis was then performed to determine the influence of each variable. The level of significance was set at $5 \%$.

\section{RESULTS}

\section{Prospective evaluation}

The clinical characteristics of the patients are reported in table 1 . Mean age was $55 \pm 11$ yrs. In total, 29 patients were followed at both hospitals, eight only at the Myology Institute and two only at the Raymond Poincaré Teaching Hospital. GAA activity was deficient in leukocytes in all patients. Genetic testing showed mutations in 11 patients, of whom six had mutations in both alleles and five in a single allele [12]. Age at symptom onset was 16-70 yrs (41 111$)$. Of the patients, five were retired, five worked full time, three worked part time and 16 were on sick leave or disability allowance.

Pain in the back, neck, shoulders and/or limbs was reported by 22 patients. Only seven patients were free of pain. Shoulder pain did not affect range of motion. Intermittent loss of bladder control was reported by seven patients and difficulty swallowing by five patients.

Of the study patients, 16 accepted to undergo Pdi measurement during volitional manoeuvres (PImax measurement) and nonvolitional manoeuvres (cervical magnetic stimulation; table 1). Significant correlations were found between VC and PImax, $P$ Imax and Pdimax, and Pdimax and TwPdi (fig. 1).

Among the 16 patients using MV, five had a tracheostomy (table 2). Age at MV initiation was $50 \pm 12$ yrs (range $20-70$ yrs). 


\begin{tabular}{|c|c|c|c|c|c|c|c|c|c|c|}
\hline Patient & Age yrs & Sex & MV & vC \% & $\begin{array}{l}\mathrm{Plmax}_{\max } \\
\mathrm{cmH}_{2} \mathrm{O}\end{array}$ & $\begin{array}{l}P \text { dimax } \\
\mathrm{cmH}_{2} \mathrm{O}\end{array}$ & $\begin{array}{l}\mathrm{TwPdi} \\
\mathrm{cmH}_{2} \mathrm{O}\end{array}$ & $\begin{array}{l}\text { Lower-limb } \\
\text { MMRC scale }\end{array}$ & $\begin{array}{l}\text { Shoulder } \\
\text { abduction degrees }\end{array}$ & Walton score \\
\hline 1 & 46 & $M$ & Y & 32 & 14 & NA & NA & 11.99 & 180 & 3 \\
\hline 2 & 59 & $\mathrm{~F}$ & Y & 37 & NA & NA & NA & 5.66 & 0 & 7 \\
\hline 3 & 71 & M & Y & 39 & 13 & 0 & 0 & 9.32 & 60 & 3 \\
\hline 5 & 52 & $M$ & Y & 29 & NA & NA & NA & 8.99 & 65 & 3 \\
\hline 6 & 47 & M & Y & 36 & 18 & 21 & 3 & 6.49 & 110 & 3 \\
\hline 7 & 58 & $\mathrm{~F}$ & Y & 29 & 22 & NA & NA & 6.50 & 145 & 6 \\
\hline 8 & 55 & M & Y & 46 & 32 & 8 & 2 & 9.16 & 180 & 4 \\
\hline 9 & 74 & $\mathrm{~F}$ & Y & 64 & 32 & 4 & $<1$ & 8.16 & 90 & 6 \\
\hline 10 & 60 & $\mathrm{~F}$ & Y & 33 & 19 & 10 & 2 & 4.00 & 30 & 8 \\
\hline 15 & 57 & M & Y & 60 & 43 & 38 & 7 & 9.50 & 165 & 3 \\
\hline 16 & 57 & $\mathrm{~F}$ & Y & 47 & 18 & NA & NA & 6.66 & NA & 7 \\
\hline 17 & 38 & $\mathrm{~F}$ & $\mathrm{~N}$ & 57 & 36 & 35 & 9 & 8.16 & 180 & 3 \\
\hline 18 & 53 & $\mathrm{~F}$ & $\mathrm{~N}$ & 86 & 69 & 90 & 25 & 8.34 & 180 & 3 \\
\hline 19 & 55 & $\mathrm{~F}$ & $\mathrm{~N}$ & 115 & NA & NA & NA & 11.00 & 180 & 3 \\
\hline 20 & 37 & $M$ & $\mathrm{~N}$ & 45 & 50 & 40 & 7 & 8.33 & 100 & 3 \\
\hline 21 & 58 & $\mathrm{~F}$ & $\mathrm{~N}$ & 64 & NA & NA & NA & 8.99 & 180 & 4 \\
\hline 22 & 74 & $\mathrm{~F}$ & $\mathrm{~N}$ & 58 & 31 & 21 & 3 & 10.16 & 180 & 3 \\
\hline 23 & 50 & $\mathrm{~F}$ & $\mathrm{~N}$ & 101 & NA & NA & NA & 9.83 & 180 & 3 \\
\hline 24 & 41 & $\mathrm{~F}$ & $\mathrm{~N}$ & 81 & NA & NA & NA & 10.66 & 180 & 3 \\
\hline 25 & 62 & $\mathrm{~F}$ & $\mathrm{~N}$ & 96 & NA & NA & NA & 8.33 & 110 & 3 \\
\hline
\end{tabular}

M: male; F: female; Y: yes; N: no; MV: mechanical ventilation; VC: vital capacity; PImax: maximal inspiratory pressure; Pdimax: maximal transdiaphragmatic pressure: TwPdi: twitch transdiaphragmatic pressure; MMRC: Modified Medical Research Council; NA: not available.

MV was initiated during an episode of acute respiratory failure in five patients (patients $1,3,5,10$, and 12 , respectively), including two patients who underwent a tracheostomy during the same episode (patients 3 and 5). The remaining 11 patients received noninvasive $\mathrm{MV}$ and met international criteria for this modality [24]. Of these 11 patients, nine had diurnal hypercapnia $>5.9 \mathrm{kPa}(45 \mathrm{mmHg})$ and the remaining two patients had nocturnal oxyhaemoglobin desaturation with morning headaches (patients 4 and 7).

Five patients underwent overnight polysomnography before and after MV initiation (patients 5, 8, 10, 15 and 16, respectively). Prior to MV initiation, the apnoea-hypopnoea index was $18,18,8,28$, and 7 , respectively, per hour of sleep and percentage of total sleep time spent with arterial oxygen saturation $\left(\mathrm{Sa}_{\mathrm{a}} \mathrm{O}_{2}\right)<90 \%$ was $5,28,1,21$, and 4 , respectively. When polysomnography was repeated in the same patients after MV initiation, the apnoea-hypopnoea index values were $0,5,5,1$, and 0 , respectively, and the percentage of total sleep time with $\mathrm{Sa}_{3} \mathrm{O}_{2}<90 \%$ were $3,21,3,0$, and 0 , respectively.
Tracheostomy was performed in two patients who failed to respond adequately to noninvasive MV (patients 4 and 14) and in one patient (patient 1) after a stroke responsible for impaired swallowing. MV modes and settings are reported in table 2. Most of the patients were ventilated with an assist-control volumetric mode and a back-up rate set two to three breaths below the awake spontaneous breathing rate, according to consensus conference guidelines [25].

When patients who did and did not use MV were compared, no difference in age was found (table 3). VC was significantly different between the two groups, as expected, but in addition differences were noted for locomotor function (table 2). Furthermore, in the univariate regression analysis, VC was significantly correlated with the Walton score, lower-limb MMRC score and shoulder mobility (table 4). The relationship between VC and the Walton score is shown in figure 2. However, it should be emphasised that six patients were able to walk without a walking aid and using only the handrail on the stairs (Walton score $=3$ ), although VC was $<50 \%$ (table 4 ; fig. 2). No parameters were significantly correlated with age 

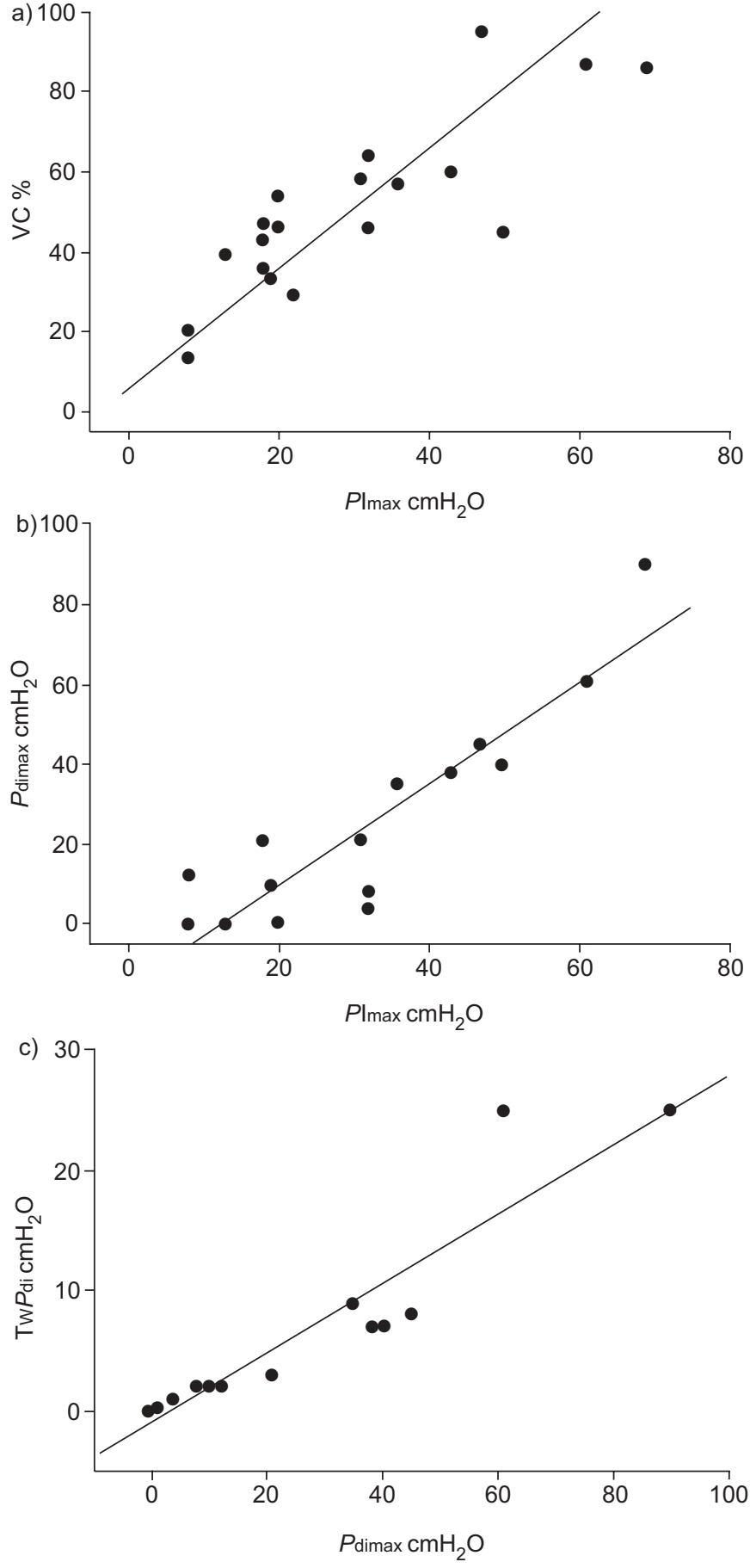

FIGURE 1. Correlations linking a) vital capacity (VC) to maximal inspiratory pressure ( $P$ Imax; $\left.\left.n=19, R^{2}=0.70, p<0.0001\right), b\right) P I \max$ to the change in maxima transdiaphragmatic pressure (Pdimax; $\mathrm{n}=16, \mathrm{R}^{2}=0.82, \mathrm{p}<0.0001$ ), and c) Pdimax to twitch transdiaphragmatic pressure (TwPdi; $n=16, R^{2}=0.88, p<0.0001$ ). The straight lines represent the regression lines.

(lower-limb MMRC scale score, $\mathrm{p}=0.61$; shoulder mobility, $\mathrm{p}=0.91$; Walton score, $\mathrm{p}=0.92 ; \mathrm{VC}, \mathrm{p}=0.60$; and PImax, $\mathrm{p}=0.96$ ). In the stepwise multiple regression model, including the parameters significantly associated with $\mathrm{VC}$ in the univariate analysis, only the Walton score was independently correlated with VC $\left(\mathrm{R}^{2}=0.198 ; \mathrm{p}=0.026\right)$.

\section{Retrospective assessment of muscle weakness progression}

Results of the retrospective VC assessment are shown in figure 3. Before MV, VC decreased gradually in most patients (fig. 3). In contrast, in the 16 patients started on invasive or noninvasive ventilation and subsequently monitored for $\mathrm{VC}$ changes, eight had an increase in VC at the first measurement time-point. None of these eight patients exhibited improvements in the Walton score or increases in body mass index. The first measurement after MV was performed during the first hospital admission following MV initiation, which occurred after 3-13 months. Among the eight patients whose VC improved, six underwent $P$ Imax measurement at MV initiation (patients 2, 8, 10, 11, 12 and 13, respectively) and at later timepoints (nonpresented data). In four of these six patients no PImax increase was found (patients 10, 11, 12 and 13, respectively). The VC improvement was $>5 \%$ of the predicted VC value in four patients (patients 3, 5, 10 and 12, respectively), who were among the five patients in whom MV was initiated because of acute respiratory failure. The Walton score is shown in figure 4. Although compliance with the follow-up program was worse before rather than after MV, the data do not suggest that starting MV may have abruptly worsened or subsequently improved the parameters reflecting locomotor function.

\section{DISCUSSION}

The present study showed a weak relationship between respiratory function and locomotor function in adults with late-onset Pompe's disease. Disease severity was not related to age. Retrospective data indicated a gradual decline in respiratory and locomotor function over time, as previously described by WOKKE et al. [26]. Interestingly, noninvasive MV initiation or tracheostomy did not seem to be associated with an abrupt deterioration in respiratory muscle function, in contradiction with the results of a review on the effects of MV [27]. However, several patients experienced a short-lived improvement in VC after MV initiation or tracheostomy.

Before discussing the implications of these findings, several methodological issues will be addressed. First, it could be argued that the youngest patient had juvenile onset (as symptoms first occurred at 15 yrs of age) and that this may have affected the results regarding correlations with age. Secondly, although the present study was mainly prospective, some data were missing and the time-course data were retrospective. Notwithstanding, the current study is one of the largest late-onset Pompe's disease series reported to date, and follow-up was $\geqslant 5$ yrs in 19 patients. Thirdly, for logistic reasons, PImax and diaphragm muscle performances were only measured in patients with severe disease. Given the shape of the normal respiratory system pressure-volume curve [28], a PImax decrease may ensure detection of respiratory muscle weakness before the occurrence of a decrease in VC. However, patients with chronic respiratory muscle weakness display a greater than expected decrease in VC related to concomitant decreases in lung and chest-wall compliance [28]. Fourthly, the Walton score is not continuous and logistic regression may, therefore, be better than least-square simple linear regression for testing the relationship between Walton score values and other variables. Nevertheless, when simple logistic regression 
TABLE 2 Mechanical ventilation (MV) modes and settings

\begin{tabular}{|c|c|c|c|c|c|c|}
\hline 1 & Y & 9 & ACV & & 700 & 16 \\
\hline 2 & $\mathrm{~N}$ & 9 & $\mathrm{ACV}$ & & 650 & 17 \\
\hline 3 & Y & 8 & ACV & & 600 & 20 \\
\hline 6 & $\mathrm{~N}$ & 9 & PSV & 14 & & 16 \\
\hline 7 & $\mathrm{~N}$ & 12 & PSV & 15 & & 14 \\
\hline 8 & $\mathrm{~N}$ & 8 & ACV & & 850 & 16 \\
\hline 9 & $\mathrm{~N}$ & 10 & PSV & 14 & & 15 \\
\hline 10 & $\mathrm{~N}$ & 8 & ACV & & 750 & 18 \\
\hline 15 & $\mathrm{~N}$ & 8 & PSV & 15 & & 12 \\
\hline 16 & $\mathrm{~N}$ & 6 & ACV & & 600 & 15 \\
\hline
\end{tabular}

Y: yes; N: no; ACV: assist-control ventilation; PSV: pressure-support ventilation.

was used to compare VC and Walton score values, the findings were unchanged $(p=0.0174)$.

Respiratory failure has been found in about one third of patients with late-onset Pompe's disease $[2,5,6]$. In a recent questionnaire study in 54 patients of the Dutch Neuromuscular Diseases Association, registered has having late-onset Pompe's disease, HAGEMANS et al. [29] found that 20 patients used ventilatory assistance, having started at a mean age of $49 \mathrm{yrs,}$ and that 23 patients used a wheelchair, starting at a mean age of 46 yrs. Fifteen patients used both ventilatory assistance and a wheelchair. Among them, three patients started both assistance modalities during the same year, six needed a wheelchair first and six needed assisted ventilation first. The

\begin{tabular}{lccc} 
TABLE 3 & $\begin{array}{c}\text { Characteristics of the patient groups with and } \\
\text { without }\end{array}$ \\
& $\begin{array}{l}\text { Patients with } \\
\text { MV }\end{array}$ & $\begin{array}{c}\text { Patients without } \\
\text { MV }\end{array}$ & p-value \\
& 16 & 13 & \\
\hline Subjects & $55.8 \pm 11.6$ & $53.4 \pm 11.1$ & 0.5788 \\
Age yrs & $39.2 \pm 13.7$ & $78.9 \pm 20.2$ & $<0.0001$ \\
VC \% & $4.8 \pm 2.0$ & $3.1 \pm 0.4$ & 0.0092 \\
Walton score & $7.8 \pm 2.0$ & $8.9 \pm 1.5$ & 0.1271 \\
Lower-limb MMRC & & & \\
$\quad$ scale & $106 \pm 57$ & $157 \pm 38$ & 0.0226 \\
Shoulder abduction & & & \\
$\quad$ degrees & $2 / 16$ & $6 / 13$ & 0.09 \\
Employed in paid job & $12 / 16$ & $9 / 12$ & 1.0 \\
Pain & & & \\
\hline
\end{tabular}

Data are presented as $\mathrm{n}$ or mean $\pm \mathrm{SD}$, unless otherwise stated. VC: vital capacity; MMRC: Modified Medical Research Council. present study corroborates these results and is the first to show a correlation between respiratory parameters and locomotor function. However, this correlation was weak. For example, patient 1 was able to walk and had normal shoulder mobility, but had a tracheostomy. Both the weak relationship between respiratory function and locomotor function and the absence of correlations between age and functional parameters indicates a need for routine respiratory function testing in adults before the development of respiratory failure, regardless of patient age or locomotor function.

Locomotor function was more severely impaired in the patients with rather than without MV, although age was similar in the two groups. Two hypotheses can be put forward to explain this finding. First, both respiratory function and locomotor function may reflect muscle weakness, as suggested by HAGEMANS et al. [29]. This hypothesis is consistent with the weak correlation between VC and locomotor function parameters. Secondly, MV may adversely affect locomotor function. However, although locomotor function was monitored more closely after than before MV, the data in figure 4 do not

\begin{tabular}{lccc} 
TABLE 4 & \multicolumn{3}{c}{$\begin{array}{l}\text { Univariate regression analysis of vital capacity \% } \\
\text { of the predicted value on other variables }\end{array}$} \\
& Coefficient & $\mathbf{R}^{\mathbf{2}}$ & p-value \\
\hline Age yrs & 0.230 & 0.010 & 0.6080 \\
Walton score & -0.032 & 0.241 & 0.0068 \\
Lower-limb MMRC scale & 0.038 & 0.220 & 0.0104 \\
Shoulder abduction & 1.03 & 0.224 & 0.0096 \\
$\quad$ degrees & & & \\
\hline
\end{tabular}

MMRC: Modified Medical Research Council. 


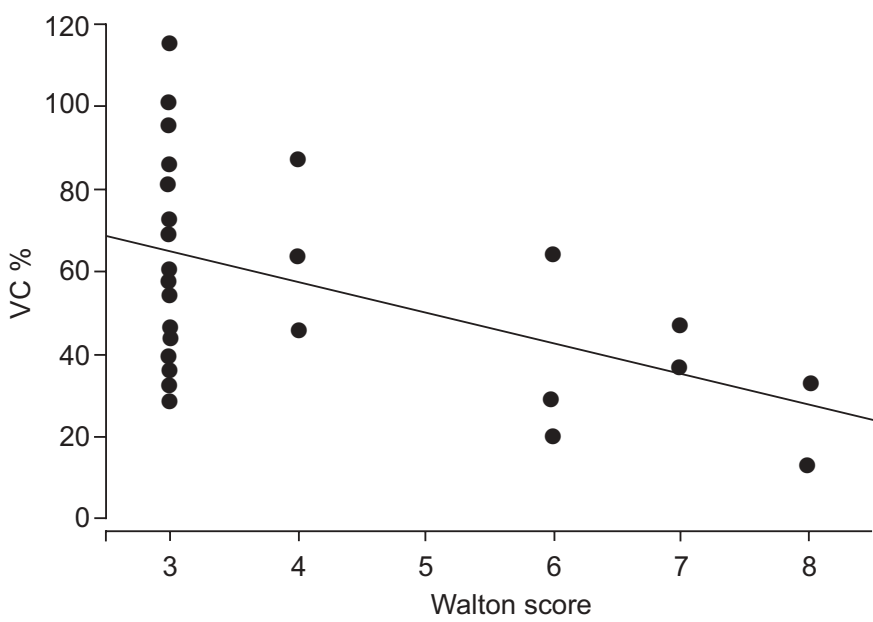

FIGURE 2. Negative correlation between vital capacity (VC) and the Walton score. The straight line represents the regression line (see also table 2).

suggest that MV initiation or tracheostomy may have caused an abrupt worsening (or improvement) in locomotor function. Thus, the first hypothesis is the most likely.

The current authors obtained information on the time-course of the muscle weakness in adults with late-onset Pompe's disease. This point is now of considerable interest, given that enzyme replacement therapy with recombinant human acid $\alpha$ glucosidase has been tested in infantile and juvenile forms and will be evaluated in adults in the very near future [7-10] Therefore, it is important to obtain data on the natural history of late-onset Pompe's disease. Interestingly, MV initiation with or without tracheostomy was found to be associated with a brief VC improvement in some patients, particularly in patients who required MV initiation due to acute respiratory failure. This is in keeping with a previous case report from the current authors' group [30]. Thus, MV may have beneficial effects, probably via an increase in lung compliance related to a decrease in diffuse microatelectasis. MV initiation and tracheostomy must be taken into account in future evaluations of enzyme replacement therapy in late-onset Pompe's disease. Another hypothesis is that acute respiratory failure may temporarily affect respiratory muscle performance. Unfortunately, the first measurement after MV was performed during the next hospital admission, which occurred after 3-13 months. Furthermore, among the four patients who experienced a VC improvement $>5 \%$ of the predicted VC, only two underwent PImax measurement. No concomitant PImax improvement was found. Nevertheless, it has been reported that a simple acute upper respiratory tract infection in patients with neuromuscular disease can cause a VC decrease related to a reduction in respiratory muscle strength, followed by a prompt improvement in VC in parallel with resolution of the infection [31]. Thus, a reduction in inspiratory muscle strength during acute respiratory failure cannot be ruled out in the current population.

In conclusion, the present study showed a gradual decline in respiratory and locomotor function over time, as well as a weak correlation between respiratory and locomotor function in adults with late-onset Pompe's disease. Respiratory and locomotor functions were not correlated with age. Age at onset
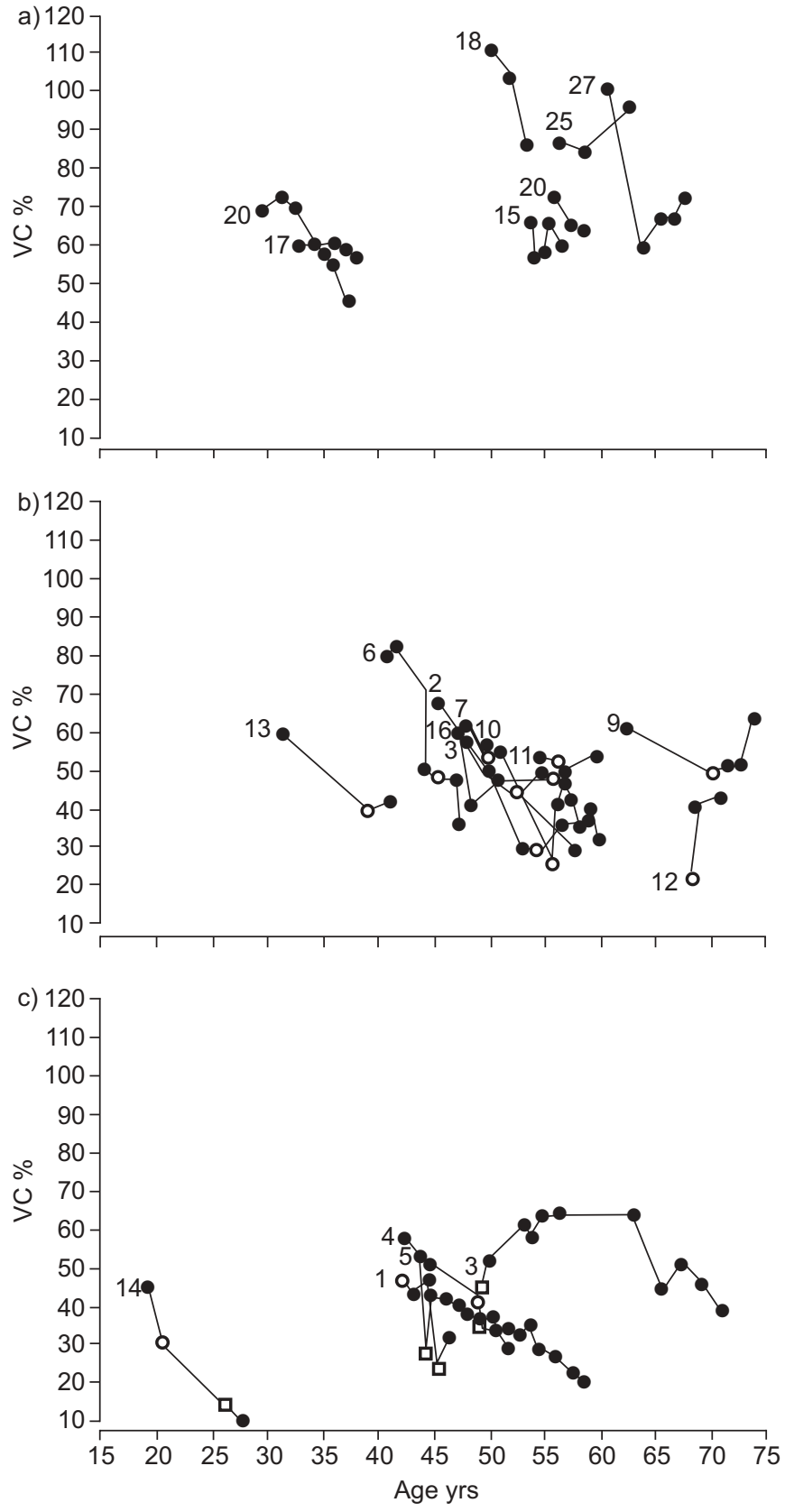

FIGURE 3. Individual results for vital capacity (VC) changes over time before and after mechanical ventilation initiation. Each patient is individualised by its number (see table 1). a) Patients for whom mechanical ventilation and tracheostomy has not been indicated. b) Patients for whom noninvasive ventilation has been indicated, but not tracheostomy. c) Patients for whom tracheostomy has been indicated. $\bigcirc$ : indicate the beginning of noninvasive ventilation; $\square$ : indicate the age of tracheostomy.

of respiratory and limb muscle weakness varied across patients. The absence of correlations with age and the weak correlation between respiratory function and locomotor function indicates a need for routine serial evaluations of both functions in patients. In addition, because mechanical ventilation and tracheostomy may improve vital capacity, they should be taken into account in future evaluations of enzyme therapy with recombinant human acid $\alpha$-glucosidase. 

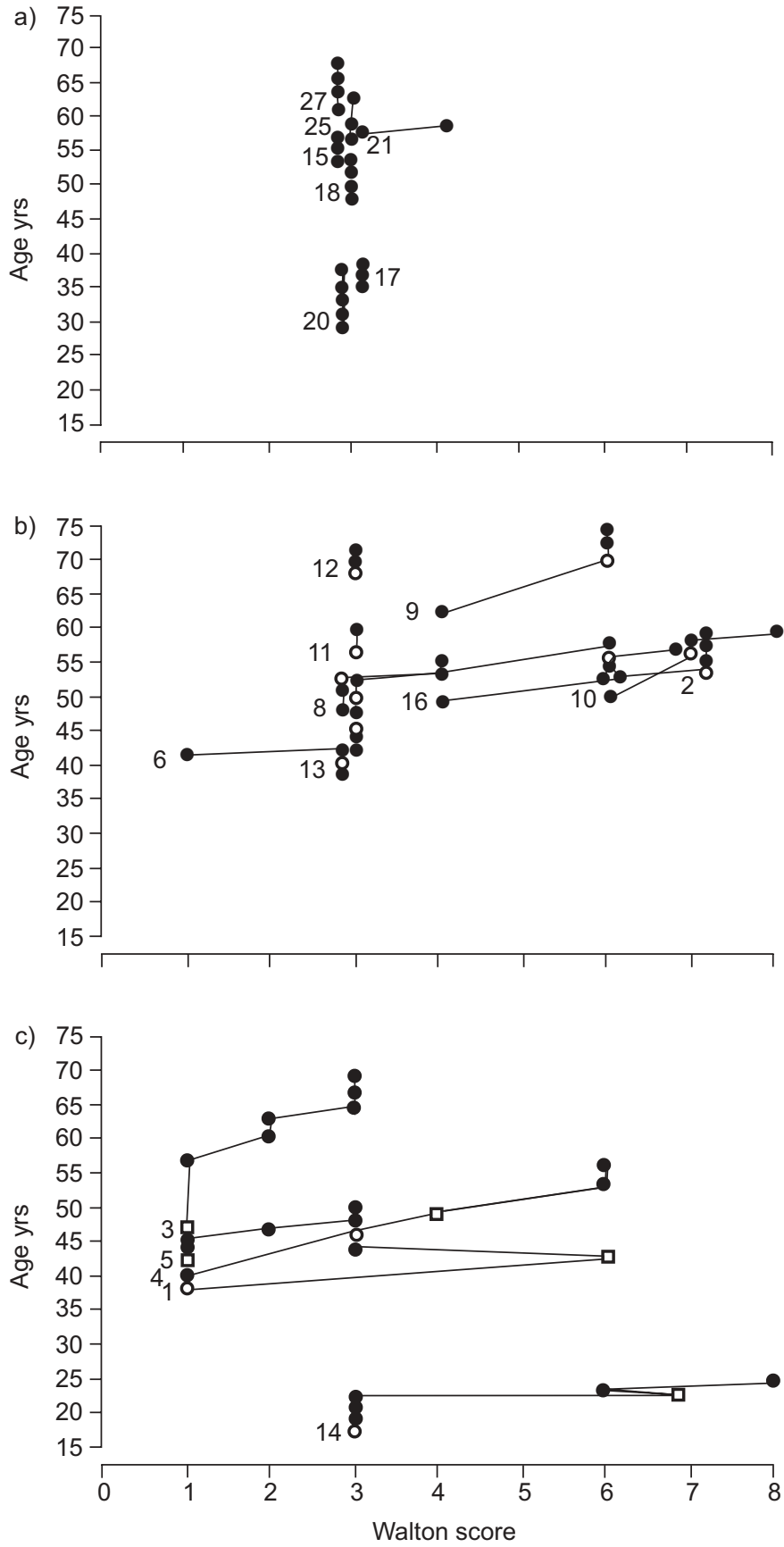

FIGURE 4. Individual results of Walton score changes with age. Each patient is individualised by its number (see table 1). a) Patients for whom mechanical ventilation and tracheostomy has not been indicated. b) Patients for whom noninvasive ventilation has been indicated, but not tracheostomy. c) Patients for whom tracheostomy has been indicated. $\bigcirc$ : indicate the beginning of noninvasive ventilation; $\square$ : indicate the age of tracheostomy.

\section{REFERENCES}

1 Engel AG, Gomez MR, Seybold ME, Lambert EH. The spectrum and diagnosis of acid maltase deficiency. Neurology 1973; 23: 95-106.

2 Rosenow EC 3rd, Engel AG. Acid maltase deficiency in adults presenting as respiratory failure. Am J Med 1978; 64: 485-491.
3 Mellies U, Ragette R, Schwake C, Baethmann M, Voit T, Teschler H. Sleep-disordered breathing and respiratory failure in acid maltase deficiency. Neurology 2001; 57: 1290-1295.

4 Engel AG. Acid maltase deficiency in adults: studies in four cases of a syndrome which may mimic muscular dystrophy or other myopathies. Brain 1970; 93: 599-616.

5 Sivak ED, Salanga VD, Wilbourn AJ, Mitsumoto $\mathrm{H}$, Golish J. Adult-onset acid maltase deficiency presenting as diaphragmatic paralysis. Ann Neurol 1981; 9: 613-615.

6 Keunen RW, Lambregts PC, Op de Coul AA, Joosten EM. Respiratory failure as initial symptom of acid maltase deficiency. J Neurol Neurosurg Psychiatry 1984; 47: 549-552.

7 Amalfitano A, Bengur AR, Morse RP, et al. Recombinant human acid alpha-glucosidase enzyme therapy for infantile glycogen storage disease type II: results of a phase I/II clinical trial. Genet Med 2001; 3: 132-138.

8 Van den Hout H, Reuser AJ, Vulto AG, Loonen MC, Cromme-Dijkhuis A, Van der Ploeg AT. Recombinant human alpha-glucosidase from rabbit milk in Pompe patients. Lancet 2000; 356: 397-398.

9 Van den Hout JM, Kamphoven JH, Winkel LP, et al. Longterm intravenous treatment of Pompe disease with recombinant human alpha-glucosidase from milk. Pediatrics 2004; 113: e448-e457.

10 Winkel LP, Van den Hout JM, Kamphoven JH, et al. Enzyme replacement therapy in late-onset Pompe's disease: a three-year follow-up. Ann Neurol 2004; 55: 495-502.

11 Dreyfus JC, Poenaru L. White blood cells and the diagnosis of alpha-glucosidase deficiency. Pediatr Res 1980; 14: 342-344.

12 Laforêt $\mathrm{P}$, Nicolino M, Eymard PB, et al. Juvenile and adultonset acid maltase deficiency in France: genotypephenotype correlation. Neurology 2000; 55: 1122-1128.

13 Walton J, Rowland L. Clinical examination, differential diagnosis and classification. In: Walton J, Karpati G, Hilton-Jones D, eds. Disorders of Voluntary Muscle. 6th Edn. New York, Churchill Livingstone, 1994; pp. 1771.

14 Kilmer DD, Abresch RT, Fowler WM Jr. Serial manual muscle testing in Duchenne muscular dystrophy. Arch Phys Med Rehabil 1993; 74: 1168-1171.

15 Black LF, Hyatt RE. Maximal respiratory pressures: normal values and relationships to age and sex. Am Rev Respir Dis 1969; 99: 696-702.

16 Heritier F, Rahm F, Pasche P, Fitting J-W. Sniff nasal pressure. A noninvasive assessment of inspiratory muscle strength. Am J Resp Crit Care Med 1994; 150: 1678-1683.

17 Uldry C, Fitting J-W. Maximal values of sniff nasal inspiratory pressure in healthy subjects. Thorax 1995; 50: 371-375.

18 Wilson SH, Cooke NT, Edwards RHT, Spiro SG. Predicted normal values for maximal respiratory pressures in caucasian adults and children. Thorax 1984; 39: 535-538.

19 Laporta D, Grassino A. Assessment of transdiaphragmatic pressure in humans. J Appl Physiol 1985; 58: 1469-1476. 
20 Baydur A, Adkins RH, Milic-Emili J. Lung mechanics in individuals with spinal cord injury: effects of injury level and posture. J Appl Physiol 2001; 90: 405-411.

21 ATS/ERS Statement on respiratory muscle testing. Am J Respir Crit Care Med 2002; 166: 518-624.

22 Laroche CM, Mier AK, Moxham J, Green M. The value of sniff esophageal pressures in the assessment of global inspiratory muscle strength. Am Rev Respir Dis 1988; 138: 598-603.

23 Quanjer PH. Standardized lung function testing. Eur Resp J 1993; 6: Suppl. 16, 5s-30s.

24 Clinical indications for noninvasive positive pressure ventilation in chronic respiratory failure due to restrictive lung disease, COPD, and nocturnal hypoventilation-a consensus conference report. Chest 1999; 116: 521-534.

25 Make BJ, Hill NS, Goldberg AI, et al. Mechanical ventilation beyond the intensive care unit. Report of a consensus conference of the American College of Chest Physicians. Chest 1998; 113 1998; 113, 5 Suppl, 289S-344S.
26 Wokke JH, Ausems MG, van den Boogaard MJ, et al. Genotype-phenotype correlation in adult-onset acid maltase deficiency. Ann Neurol 1995; 38: 450-454.

27 Vassilakopoulos T, Petrof BJ. Ventilator-induced diaphragmatic dysfunction. Am J Respir Crit Care Med 2004; 169: 336-341.

28 Tobin MJ. Respiratory muscles in disease. Clin Chest Med 1988; 9: 263-286.

29 Hagemans MLC, Winkel LP, Van Doorn PA, et al. Clinical manifestation and natural course of late-onset pompe's disease in 54 Dutch patients. Brain 2005; (In press).

30 Vercken JB, Raphael JC, de Lattre J, Fromageot C, Fanjoux J. Adult maltase acid deficiency myopathy: treatment with long-term home mechanical ventilation. Biomed Pharmacother 1988; 42: 343-349.

31 Poponick JM, Supinski G, DiMarco A. Effect of upper respiratory tract infection in patients with neuromuscular disease. Am J Resp Crit Care Med 1997; 156: 659-664. 